CERN

\section{Kendrew takes knife to high-energy physics}

The technical consultant to the Kendrew committee on British involvement in highenergy physics, Dr Christopher Llewellyn-Smith, had repudiated the committee's chief conclusion (see Nature 29 May, p.266) within minutes of its formal publication earlier this week (High Energy Particle Physics in the United Kingdom). Of the recommendation that Britain should seek a reduction in its contribution to CERN, the Geneva highenergy physics laboratory, of "at least 25 per cent by 1991", Llewellyn-Smith says that the "unsubstantiated assertion" that such a reduction could be attained without detriment to CERN's position is, simply, "false".

That the Kendrew report would be contentious has always seemed probable. In the event, however, the report is a model of clarity, which should comfort both its supporters and its critics. Briefly, the conclusions are that Britain should remain a member of CERN "on the present basis" until 1989, but that it should continue beyond that time only if that can be done "at significantly lower cost". The timing is determined by the construction programme for the new electron collider LEP.

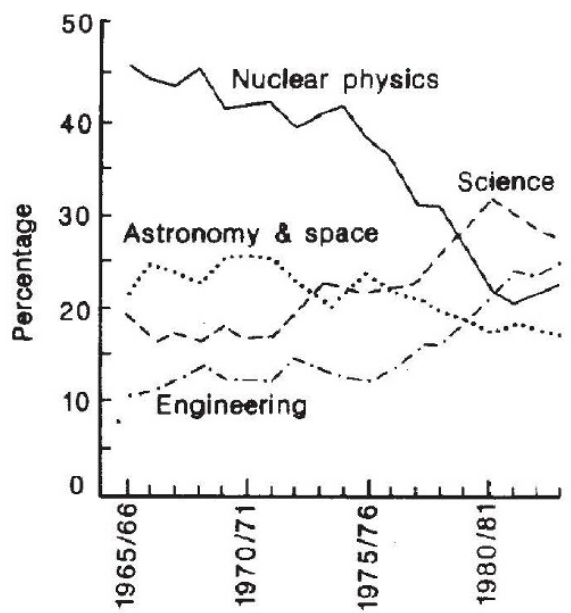

The committee notes that British scientists continue to make important contributions to high-energy physics and that the subject is at present at an exciting stage, but it also says that British spending on high-energy physics is too great a proportion of the present or "any realistic" budget of the Science and Engineering Research Council (SERC). It recommends that modest economies should be made as soon as possible, principally in the budgets of groups working on experiments at CERN, does not expect these to be substantial before the financial year 1988-89, but would expect them to increase to "at least 25 per cent"by 1991.
The committee says that the proposed reduction of the CERN budget would be an "attainable adjustment" that would "still allow the laboratory to maintain itself at a world class standard albeit at a reduced pace of development". The proposed reductions of domestic expenditure would entail "a significant decrease in the sizc of the cxpcrimental community" (now estimated to consist of 400 senior people and 240 graduate students), but the committee says that it should be possible to arrange for an orderly contraction while maintaining an "appropriate" British contribution to the field.

The report argues that the financial circumstances of the United Kingdom which have led the committee to its conclusions "may not be unique" among CERN members, that "the overall level of expenditure on the subject is too high" and that "it would not be counter to the long-term interests of the field" if the pace of development were reduced "worldwide and not merely at CERN"

The committee acknowledges that the total budget of CERN has decreased by 20 per cent in real terms over the past decade, and that British spending on highenergy physics has declined during the same period "from what was an extraordinarily high level". It also says that there is insufficient support for first-class research proposals both in high-energy physics and in other areas.

The report suggests that there is at present little room for manoeuvre within the British budget, pointing out that there would be no point in remaining a member of CERN if it were not a first-class laboratory and if domestic funds were insufficient British physicists to make full use of it. The report also says that there is a "strong moral obligation" on the United Kingdom to remain a member of CERN until LEP is finished as well as to continue development of the three particle detectors being built for use with LEP.

The Kendrew committee therefore argues that the British delegation to CERN should press for an immediate review of the financial structure of the CERN laboratory, with the objective of reducing costs after 1989 . Allowing for both domestic savings and reduced expenditure at CERN, the committee calculates that it should be possible to save a total of $\$ 55$ million over the next seven years, or an annual $\$ 13.8$ million (at present prices) in 1992-93 and succeeding years. The Kendrew committee asks that the British government should help to avoid future difficulties by arranging that the budgets of the research councils will not be further eroded by inflation, and that the research councils should be insulated from fluctuations of exchange rates.

The committec goes on to say that even the saving likely under its proposals will not "in itself solve the financial problems of other areas of science". and that extra funds will be needed if the British research base is to meet "the challenges of the next decade".

Formally, the report is a recommendation to SERC and the Advisory Board for the Research Councils, on whom will fall responsibility for deciding what should be done. The most likely next step is that negotiations will be opened with CERN on the proposed reduction of the budget. Most probably, there will be no biting of bullets unless and until those negotiations seem about to fail.

\section{Informed dissent}

ThF dissenting opinion from Dr Christopher Llewellyn-Smith, reader in theoretical physics at the University of Oxford, is strong meat. It begins by saying that the real issue facing the whole of British science is "the erosion of our superb scientific tradition" by the inadequacy of funds. Llewellyn-Smith says that he informed the Kendrew committee of his dissenting opinion before making it public.

Among Llewellyn-Smith's objections are the following.

- The demand that the British contribution to CERN should be reduced by 25 per cent implies a similar reduction of the total budget.

Given that salary costs at CERN are roughly half of the total budget, reducing the budget by a quarter would require either a disproportionately larger cut of scientific activity or a reduction of the staff employed (which would not yield immediate savings because of the high cost of redundancy).

- It is inconceivable that the necessary two-thirds majority for a 25 per cent cut in the CERN budget could be found among the present membership, for which reason the committee's main conclusion "implies withdrawal . . the committee fails to face up to this consequence."

- The suggestion that the proposed domestic reduction of 25 per cent could be orderly "is ludicrous"; because of the long timescale of high-energy physics experiments, the cuts would fall on those whose projects are about to be completed.

As recently as 1981, SERC offered the opinion that the budget for nuclear physics should remain constant, since when highenergy physicists have made long-term commitments.

The recommendations in the report would seriously damage particle physics, would damage the credibility of the United Kingdom as a collaborator in science projects and yet would make only a small contribution to the "solution of the crisis in science funding". 